\title{
The benefits of preserving and promoting cultural heritage values for the sustainable development of the country
}

\author{
Khoa Vu Hoang \\ Language Department, FPT University, Vietnam
}

\begin{abstract}
Cultural and natural heritages are considered invaluable resources, creating a unique tourist attraction for each country. However, knowing how to use this heritage for sustainable tourism development, while preserving and promoting the heritage value for future generations is not a simple task. This article focuses on the values of cultural heritage and the importance of maintaining and promoting it while integrating with the environment for the development of society. It discusses the current state of cultural heritage preservation and promotion in Vietnam, showing examples of development with disregard to the heritage and the environment, why it is necessary to have sustainable development in active culture conservation, as well as the relationship between the preservation, promotion of the cultural heritage and the socioeconomic development and the environment. A perspective on the cultural heritage value in sustainable development is also given. Through the reading of supporting materials and the comparison of survey data, it is clear that the preservation of cultural values not only contribute directly to the socio-economic development of a country similar to Vietnam, but also to help create new values in later generations. Therefore, it is concluded that a sustainable approach to the conservation of cultural heritages is very important for the future handling of such irreplaceable resources.
\end{abstract}

\section{Introduction}

To protect, preserve and promote the values of national cultural heritage, Vietnam has achieved many outstanding achievements, many of which are of international significance, thanks to the effective use of tourism activities. It had not only helped promote heritage values, but also brought practical benefits to the community such as introducing Vietnam's beauty and culture to the world. Most notably, in 2017, Ha Long Bay (Quang Ninh province) welcomed more than 3.6 million visitors, including 2.4 million international visitors, collecting about 1,100 billion VND from ticket sales. Monuments of the ancient capital of Hue welcomed about 3 million visitors, including more than 1.8 million international visitors, collecting more than 320 billion VND from ticket sales; Hoi An Ancient Town (Quang Nam Province) welcomed 1.96 million visitors, earned 219 billion VND from ticket sales, etc.

Thus, it can be seen that there is a close relationship between the conservation and promotion of cultural heritage and tourism development. If we can learn how to use this relationship more effectively, it can be a great resource to help create a more sustainable stream of revenue for tourism in the long-term future, in turn promoting social economics growth [1].

While there might be rapid economic growth from the tourists, without proper conservation, it is evident that there would be change and loss of the original heritage [2]. In exchange for infrastructure such as eco-tourism, resort, cable car systems, hundreds of thousands of hectares of forests have disappeared, many beautiful beaches have been deformed, many mountains have been destroyed, and with that is the change of natural ecosystems as well as the cultural environment of the community in the area. In Asia, UNESCO has voiced a warning to Indonesia when the indigenous culture in Poland has almost disappeared due to "hot" tourism development. The ancient capital Ayutthaya, a famous international cultural heritage in Thailand, has also caused problems to the country's government. Notably, the Elbe valley in Germany had to be withdrawn from the list of world heritages due to socioeconomic development [3].

\section{Methodology}

The study was started by carrying out the literature review and documentary source. Sources were selected 
with the intention of finding the correlation between tourism and cultural heritage exploitation. More recent studies were preferred, as it is more accurate and relevant to the future of cultural heritage preservation.

\section{The current state of cultural heritage preservation and promotion in Vietnam}

According to UNESCO, Ha Long Bay, a natural heritage of Vietnam, had been under observation by the UNESCO due to the rapidly changing site and environment caused by economic and tourism development. In many cases, even the press had to step in and make a call to action, such as when the caves in Ha Long Bay became the venue for lavish gala dinner for tourists, when Thien Duong cave (Quang Binh province) was in danger of becoming the venue for the Miss World Peace Contest 2017, when tourism investment projects in Son Tra peninsula was damaging the landscape and ecosystem the "green lung" of Da Nang, or plans for exploitation and a cable car system in Son Doong cave (Quang Binh province) (Figure 1).

Recently, a huge tourist project suddenly sprung up in the middle of the world cultural and natural heritage area of Trang An (Ninh Binh province) without a license. The second Lady Chua $\mathrm{Xu}$ statue was also secretly constructed by the enterprise on Sam mountain (An Giang province). Although these works were forced to be dismantle, the damage they cause to the heritage landscape and ecosystem is irreversible [2]. Obviously, if the dialectical relationship between tourism development and heritage conservation and promotion is not seen objectively, and in a complete and clear manner, the tourism development will only bring short-term benefits but cause long-term consequences [4].

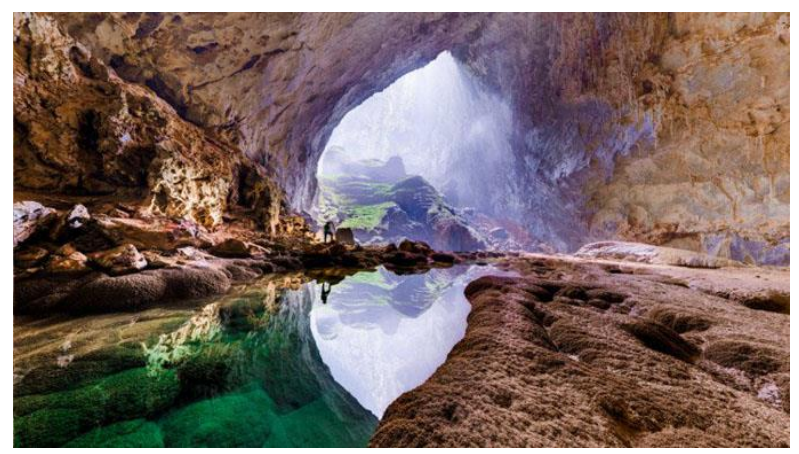

Fig. 1. Son Doong Cave

\section{Reasons for sustainable development in active culture conservation}

When tourism is identified as one of the key economic sectors of the country, the requirement for sustainable tourism development associated with heritage value conservation becomes more urgent than ever [5]. The national tourism development model needs to be planned for the long term through the rational, effective and humanistic usage of our natural and cultural resources left by our pioneers, the success of which should not be measured only by profit, but also by the future benefits we might get [2]. In addition, to ensure the sustainability of non-renewable resources, economic projects, cultural objectives should also be approved. Furthermore, in order to ensure balance of immediate economic interests and long-term cultural goals and regulate future projects better, a clear set of institutionalized rules for investment activities and economic development should be realized [3].

More specifically, in the state of Virginia in America, a study showed the contrasting differences in the spending of tourists at a site where they there is no heritage activities, compared to a site that had heritage activities. The result is that visitors stayed for longer, visited more places. It also showed that visitors would be more likely to spend 2.5 times more than visitors. In the world, this trend is also observed, as heritage visitors stay for more days and they spend more. From this, it is clear that it would have a very positive impact on the local economy [6]. Biltmore is a great estate located in North Carolina; whose management also commissioned a study of its financial impact to the local area. The results are clear: 760 jobs, $\$ 215$ million to the locals, $\$ 5$ million in taxes, $\$ 9.5$ in direct payroll, and $\$ 8.4$ million in indirect payroll. A more shocking figure was also discovered, that for every $\$ 1$ that tourists spent at Biltmore, they also spent $\$ 12$ elsewhere locally, whether it was a hotel, restaurant, gas station, retail store, etc. Biltmore not only drew in customers for the local heritage site, but consequently for the local area as well [7].

Heritage is an irreplaceable tourism resource, and in order to address the relationship between heritage conservation and sustainable tourism development, it is necessary to respect the original heritage [8]. In the past, many legacies have been restored and renewed without respect to the original, leading to the distortion of the heritage. Today, scientists have introduced the concept of "active conservation". This helps to not only preserve the inherent values of the heritage, but also promote those values and bring them to life. To apply this concept in the real world however, heritage workers must work in close collaboration with tourists [9]. Tourism development projects associated with heritage exploitation must have careful planning and consultation from heritage experts to assess in detail the full impact of tourism to the heritage, thereby ensuring proper measures can be taken to control the impacts at the suitable level (Figure 2). When planning tourism spaces, it is also crucial to not exceed the maximum capacity of the site so as to not damage the environment and its resources [3]. Then, the number of tourist (both domestic 
and international) will increase as a result of the reasons mentioned above.

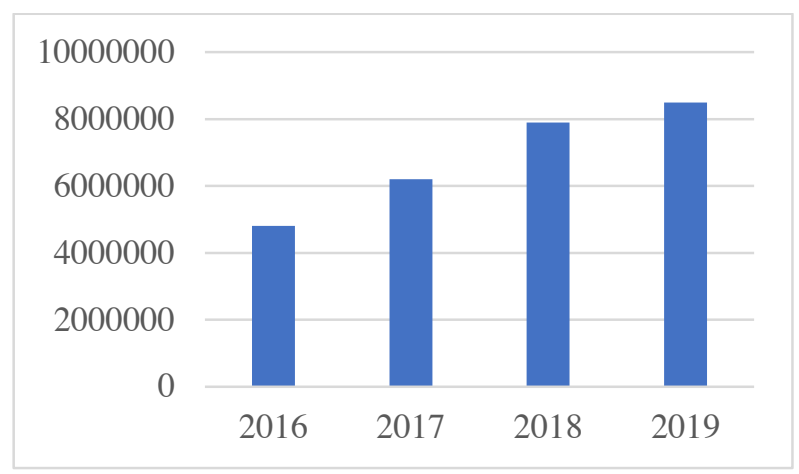

Fig. 2. The number of foreign visitors traveling to Vietnam (General Statistics Office of Vietnam)

In fact, it should be noted that the concept of linking heritage with tourism development does not mean that all heritages are allowed to be exploited for tourism, and they must be preserved [1]. When developing tourism in heritage sites, it is necessary to not only appease the interests of stakeholders and the local communities but to also focus on heritage restoration and conservation [10].

\section{The relationship between cultural heritage conservation, socio-economic development and the environment}

It is not always possible for the preservation of historical-cultural relics to go hand in hand with socioeconomic development, especially in urban space. This is not unique to developing countries, as developing countries also suffer from this problem. In quite a lot of cases, this conflict often ends with the socio-economic development side coming out on top [11].

On closer inspection however, the conservation and promotion of cultural heritage values and socioeconomic development are not two opposing sides but a unified entity, all towards the common goal of sustainable development [2]. In Vietnam, this conflict is abundant in many facets of heritage conservation and exploitation.

Historical or cultural relics is an irreplaceable part of history. Because of that, if we change it in any way shape or form, then the value and authenticity of the relic is lost. Therefore, it is necessary to strictly comply with the rulings of the Cultural Heritage Law regarding the heritage sites. For relics (archaeological relics) unearthed when building socio-economic works, a heritage management agency must be notified to help solve the problem of conservation and development [10].

In other countries around the world, to harmonize the conservation of archaeological relics and construction of socio-economic development works, one of these three solutions are often applied. In France:
First, if the relic has been determined to have a special value and there is an economical, technological benefit to preserving and promoting it directly at the site, then an on-site conservation project called an "Open-air museum" for research, sightseeing and tourism is built.

Second, if the relic is determined to have an important value, but it is not suitable for onsite conservation, the excavated artifacts can be preserved and displayed in a museum; cover the entire surface of the excavation hole with geotextile, then layer it with sand and hand over the site to the project owner. When the time is right, re-excavate [12]. There should be signboards marking the landmark and introducing the relic above the surface of the excavation hole.

Third, if the relic is of value, and it is unsuitable to conserve it onsite, but the building of socio-economic developmental works (such as making roads, etc.) should be given priority then right after the archaeological excavation is completed, all documents and artifacts should be transferred to the museum to continue with the research, display and promotion of the relic; at the same time, excavation holes should be filled, then handed over to the project owner to continue construction of the developmental works [8].

International organizations have also given their recommendations: When formulating policies and implementing socio-economic development projects, there should be input from the beginning of three parties: managers, project owners, relevant sector specialists and communities that are affected by the project [9]. The active coordination between the four parties mentioned above will ensure the legality and practicality in harmoniously solving the relationship between heritage conservation and socio-economic development.

The exemplary solutions to harmonize cultural heritage conservation with socio-economic written above show that while solving these problems might not be easy, they are in fact possible. In order to proactively prevent possible conflicts in the future, during the planning and preparation of planning projects, it is necessary to have active coordination from related industries, such as construction, architecture, transportation, electricity with the cultural sector to study the existence of heritage sites in the project area so that the sites remain unaffected by the project [4].

Besides the relationship with socio-economic development, cultural heritage conservation also goes hand in hand with protecting the environment [13].

For example, developing without care near the cultural site is a contributing factor to the destruction of the environment. Recent times in Ghana, the factors that play a part in the degredation and destruction of the environment is rapidly becoming more complex, the main source of which can be attributed to commercial factors, such as the exploitation of natural resources [14]. For Ghana, agriculture is the main contributor of the local economy, is the main cause for the deleption of 
forest resources in the area. The need for agricultural land and natural resources leads to deforestation, causing harm to the forest and wildlife in the area. As the population grows with the increase of migrants, population growth also affects the growing demand for land, which in return leads to more pressure on land and other natural resources. A lack of respect for the cultural heritage and practices, and the failure to enforce rules preventing damage to the environment might be negative consequences impacting the beautiful landscape of Akyem Abuakwa.

Another example is the destruction of historical buildings and cultural heritage sites in an urban environment. A quarter of everything at a landfill in the United States is said to be construction deris. This is very alarming, because destroying a typical commercial building in America could mean losing not the environmental benefit of recycling over 1,344,000 soft drink cans, but the time it took to diligently sort and recycle them [15]. Likewise, in the context of reducing carbon footprint in cities, the best way and the most sustainable way to lower cost and increase energy effectiveness is to reuse existing buildings, and avoiding demolition or reconstruction [16].

\section{Perception of cultural heritage value in sustainable development}

In the world, there are many different perspectives on development of a country, in which there is a tendency to consider economics, science and technology as the foundation [3]. While it is true that the three areas mentioned are very important, development is a complex multidimensional problem. To solve this problem, it is imperative that we do not look at it in a single angle, but rather how they interact with each other. Furthermore, the utmost fundamental nucleus of development is from the qualities of man, intelligence, creativity, humanity, which is represented by our vast cultural history.

The concept of "sustainable development" first appeared in the "World Conservation Strategy" issued in 1980 by the World Conservation Association, the forerunner of the International Union for Conservation of Nature (IUCN). Later, it is redefined in the report "Our Shared Future" by the International Commission for Environment and Development (WCED) in 1987 at the Conference on Environment and Development of the United Nations. In 1992, another meeting held at Rio de Janero improved on the concept, and at the 2002 World Summit in Johannesburg, the concept was finalized. In recent years, the issue of sustainable development is quickly becoming one of the top concerns of humanity not only forums and documents of the international community but also in the Development Strategy and the Agenda of Nations. The United Nations has launched the 2030 Agenda consisting of 17 general goals and 169 specific goals for sustainable development [12].
Up until now, the true definition of the concept of sustainable development is still somewhat mixed. However, it can be generalized as such: Sustainable development is the development that ensures the development needs of the current society without harming the development capacity of the future generations; it is the binding between economic growth, cultural development, social justice, and environmental protection; it means to use resources and all existing resources of the society in an efficient yet responsible manner not only for development in the present but also for the generations to come [8].

Vietnam's history and culture are not only saved in books, but also present in all parts of the country by thousands of historical and cultural relics, and with it a cornucopia of heritage. It exists in the form of intangible culture with its artistic textures and important spiritual and scientific values [2]. It provides ideas and lessons that today's generation can recognize and learn from, such as good traditions, profound and rich knowledge about all facets of mankind. Although cultural heritage is never explicitly mentioned in international documents on sustainable development as well as in the Vietnam Sustainable Development Strategy however, through the viewpoints, objectives, priorities and solutions outlined in the Strategy, we can narrow it down to the following thoughts about the conservation and promotion of cultural heritage for sustainable development.

First, the trend of today's world is that the conservation and promotion of cultural heritage values, both tangible and intangible, must be directed to communities currently living in the heritage site and tourists. Because the historical or cultural relics are the brainchild of their communities foremost, they are directly involved in promoting and conserving these cultural heritages. And according to the 2003 UNESCO Convention on the Protection of Intangible Cultural Heritage, communities, groups of people or even individuals, play a very important role in the protection, maintenance, practice and reproduction of the intangible cultural heritage, especially the artisans or the locals themselves, helping enriching cultural diversity and human creativity.

Of course, historical or cultural relics are from the past, but living in the modern era, they must be able to relate to the people of the modern era to become an organic part of contemporary life. In the process of implementing heritage conservation projects, it is necessary to raise awareness and understanding of the value of the heritage for the local community to help them understand their role and responsibility in the protection of their own heritage. Practical actions such as training future artisans, providing new members of the community knowledge about the heritage, directly teaching the skills required to adapt their heritage for tourism are all necessities in the process of promoting and conserving the heritage. 
For communities living in natural heritage areas especially, in addition to creating conditions and encouraging communities to apply their knowledge of the heritage, there should be a call to action to prevent the overexploitation of natural resources. A good starting point is helping them understand the effects of overexploiting natural resources could have to their own heritage and livelihoods.

Economical and efficient use of resources, especially non-renewable resources should also be looked at. Cultural and historical sites are to be considered a kind of non-renewable "resource". With the help of various traditional technical solutions combined with modern science and technology, it is possible to keep the "original element constituting the heritage" (according to the term of the Law on Vietnamese Cultural Heritage), or "authenticity", "integrity", "Global Outstanding Value" of heritage (in terms of the 1972 UNESCO Convention on the Protection of World Natural and Cultural Heritage). To preserve and exploit the relic value in a responsible way for the sustainable socioeconomic development, is to preserve this kind of "nonrenewable resources" for future generations. However, the phenomenon of restorations that distort the value of the relic or even leaving old relics to build new heritage works on top of the old is still at large. The cause can often be traced back to very owner of the heritage. A common occurrence is that they are not aware of the true value of relics, not strictly complying with the Law on Cultural Heritage on the preservation, restoration of heritages; the Government's Decree also regulates the procedures for formulating and approving the planning and projects for preservation, restoration of historicalcultural relics and scenic spots. These mistakes not only degrade the cultural value of the heritage, but it also directly causes damage to sustainable development. As UNESCO's Global Declaration on Cultural Diversity stated: Heritage in all its forms must be preserved, promoted and passed on to future generations as a database of experiences and human aspiration, to increase creativity in all its diversity and inspire dialogue between cultures.

Each type of cultural heritage needs a unique conservation approach and method, but it is certainly needed for each type of discipline. The conservation and promotion of cultural heritage values not only benefit from research results of social sciences (history, archeology, ethnography, Han Nom, folklore, fine arts, architecture, etc.), but also many contributions from natural sciences (physics, chemistry, biology, geology, construction, etc.). Therefore, in order to preserve and promote the value of cultural heritages under the impact of natural disasters and climate change, organizations directly managing heritages need to lend a helping hand to find scientific solutions to limit the harmful effects of natural disasters, adapt to climate change effectively.
Only then, will the conservation and promotion of cultural heritages be truly sustainable.

For intangible cultural heritage, although many great and significant results have been achieved, there has been a new approach to conservation and value promotion of this vulnerable asset; in fact, there are many types of intangible cultural heritages that are facing many challenges and disappearance, such as oral heritages, folk knowledge, social practices etc. Cultural space changes have changed heritage practices. The number of people practicing the heritage is dwindling, while the financial resources to conserve and promote the heritage are few and far in between. The same is still true today, as the local community is still largely responsible for protecting, preserving and promoting the value of cultural heritage. As time goes on, the heritage gradually changes form and texture on a fundamental level, and the culture today might not be the same tomorrow. This is true of traditional festivals, where as they were simpler and more rudimentary but showed more heart, the modern festivals are much larger in scale. The value of the old festivals might have been changed over time, but looking at the interest of the new generation in older cultural heritages, it suggests that it is up to how they are managed that affects if the change is for the better or for worse. Therefore, the main party responsible for preserving and promoting the heritage, the local community, should work in collaboration with cultural experts and the local authority, as it would not only in return help the local community grow, but also bring the important values to other people.

Third, we should try to mitigate the harmful effects of natural disasters and proactively adapt and effectively to climate change, especially against the rise of sea level. A prominent feature of the historical-cultural heritage in our country is very diverse and rich in types (historical communal houses, temples, pagodas, citadels, mausoleums, , palaces, historical houses , historical sites) using a wide range of materials (brick, stone, wood, bamboo, leaves), many of which is composed from organic material, which can fall victim to deformation, mold, termites, spoilage, degradation, humid heat, storms, floods and especially climate change. Vietnam is a country with a coastline of nearly $3,500 \mathrm{~km}$ with more than 2,773 islands of all sizes. Along the coast and on those islands, many famous archeological artifacts and ancient wreckages act as proof of our country's economic and cultural trade with the world early in the historical timeline; historical buildings marking our fight for independence against colonialism; many famous landscapes and biosphere reserves registered by UNESCO, etc. are also tasked with preventing the climate change and rising sea level.

The task of preserving and extending the "longevity" of historical-cultural heritage, a type of "non-renewable resource", under current climate change conditions is a great challenge to us. In addition to the application of 
traditional conservation methods and modern science and technology, it is necessary to research and digitize data on historical-cultural relics and landscapes to be able to exploit and share an open database for management, research and exchange of information in heritage conservation and promotion [8].

Next, we need to conserve and develop biodiversity. Vietnam is classified as having high biodiversity. Among the natural heritages, there are 3 registered by UNESCO as World Natural Heritage: Ha Long Bay is registered twice (the first time in 1994 for beauty, the second time in 2000 for the geomorphology, and now Hai Phong city is working with Quang Ninh Province to develop a dossier to submit to UNESCO to register Ha Long Bay - Cat Ba Archipelago as a World Heritage Site of Biodiversity). Phong Nha - Ke Bang National Park is also registered by UNESCO twice (the first time in 2003 for geomorphology, the second time in 2015 for biodiversity). The Trang An scenic complex consists of 3 parts that make up the Global Outstanding Values, the geological value of the landscape, primeval forest value of Hoa $\mathrm{Lu}$ and historical-cultural value. Vietnam also has national biosphere reserves registered by UNESCO, natural heritage sites of ASEAN, etc.

With the quest for biodiversity, it is also important to apply sustainable development. With the ever-changing conditions of ecosystems, it is necessary to study and implement solutions to limit the decline or disappearance of some endemic species while preventing the invasion of alien species. Interdisciplinary cooperation with relevant organizations and application of modern science and technology should be applied to manage, conserve and develop biodiversity [12].

Finally, we need to strengthen management capacity for developing human resources to have sustainable development. The goal of developing human resources is to build a team of professional managers and professionals, a team of skilled people equipped with the full understanding of the Law on Cultural Heritage and related legal documents in order to preserve and promote the value of historical-cultural relics and landscapes.

Due to the specific nature of the human resources involved in heritage management and conservation, if we want to be able to hand over the responsibility, it must start from education. A good basis for this is education at the university level, where students are beginning to learn fundamentals about the many facets of many fields. A focus on training experts of relic conservation is also mandatory, as workers, and an effective strategy to use is direct training at the site ("onshore workshop"), preferably with application of modern teaching techniques and advanced machinery, technology [10]. A focus on education of the local residing community at the heritage site or landscape is also a must, as they are directly involved in the process of conservation and promoting. It is advised to not only teach technical details in which to maintain the heritage, but also to provide them with the skill that they might need in areas related to conservation and promotion, such as tour guide skills, experience tourism skills, etc.

\section{Conclusion}

The treasure of historical-cultural relics, landscapes and intangible cultural heritages left by our ancestors is not just a great and valuable asset, but also a resource for sustainable development. With the globalization of the world, the cultural value of these heritages is becoming ever more important, representing the spirit and wisdom of an entire nation of people. This great asset that could potentially be destroyed and forgotten if it is developed recklessly. Moreover, it could directly leave a negative impact to the environment, and the socio-economic development of the area, and of the whole nation. It is understood that when communities try to promote the local heritage without proper regulations and help from professionals, it could easily damage the site and potentially degrade the values of the cultural heritage. Therefore, it is a necessity to have that cooperation between government officials and the local community when dealing with cultural sites and heritages.

Acknowledgement. The paper is completed thanks to the kind support of colleagues as well as my advisor.

\section{Conflict of interest}

No conflict of interest is noted in the paper.

\section{References}

1. Yang, Y., Shafi, M., Song, X., \& Yang, R. Preservation of cultural heritage embodied in traditional crafts in the developing countries. A case study of Pakistani handicraft industry. Sustainability, 10, 5 (2018).

2. Caust, J., \& Vecco, M. Is UNESCO World Heritage recognition a blessing or burden? Evidence from developing Asian countries. Journal of Cultural Heritage, 27 (2017).

3. Thang, H. Q. Tourism With the Integration and Development of Vietnam-Southeast Asia. International Relations, 6, 3 (2018)

4. Yang, Y., Shafi, M., Song, X., \& Yang, R. Preservation of cultural heritage embodied in traditional crafts in the developing countries. A case study of Pakistani handicraft industry. Sustainability, 10, 5 (2018).

5. Fusté-Forné, F., \& Nguyen, T. Communities of Practice, Identity and Tourism: Evidence on Cultural Heritage Preservation in World Heritage Sites. Almatourism-Journal of Tourism, Culture and Territorial Development, 9, 18 (2019).

6. Donovan D. Rypkema. Virginia's Economy and Historic Preservation: The Impact of Preservation on 
Jobs, Business, and Community. Preservation Alliance of Virginia. (1995)

7. Donovan D. Rypkema. Profiting from the Past: The Impact of Historic Preservation on the North Carolina Economy. Preservation North Carolina (1998).

8. Dang, L. N. T. Preserving and Promoting Colonial Architecture. Culture and Local Governance, 6, 2 (2019).

9. Son, L. M., \& Dang, L. N. T. Preserving and Promoting Colonial Architecture: Heritage Conservation and the Challenge of Urban Development in Da Nang City. Culture and Local Governance/Culture et gouvernance locale, 6, 2 (2019).

10. Othman, A. A. E., \& Elsaay, H. Adaptive reuse: an innovative approach for generating sustainable values for historic buildings in developing countries. Organization, Technology and Management in Construction: an International Journal, 10, 1 (2018).

11. Lordkipanidze, M., Brezet, H., \& Backman, M. The entrepreneurship factor in sustainable tourism development. Journal of cleaner production, 13, 8 (2005).

12. Linh, T. D., \& Minh, D. D. The influence of practicing spiritual tourism on the environment in Chau Doc-An Giang-Viet Nam. Science \& Technology Development Journal-Social Sciences \& Humanities, 3, 1 (2019).

13. Wells, Jeremy \& Stiefel, Barry \& Bliss, Annamarie. Human-Centered Built Environment Heritage Preservation: Theory and Evidence-Based Practice. (2018)

14. Awuah-Nyamekye, Samuel \& Sarfo-Mensah, Paul \& Amisah, Steve \& Owusu-Bi, Akwasi. Environmental Conservation and Preservation of Cultural Heritage. Worldviews: Global Religions, Culture, and Ecology. 18 30-53. (2014)

15. Rypkema, Donovan D. "Heritage conservation and the local economy." Global Urban Development Magazine 41 (2008)

16. Yung, E. H., \& Chan, E. H. Implementation challenges to the adaptive reuse of heritage buildings: Towards the goals of sustainable, low carbon cities. Habitat International, 363 (2012) 